\title{
Snow-creep forces on masts
}

\author{
Jan Otto Larsen \\ Department of Geotechnical Engineering, Norwegian University of Science and Technology, N-7034 Trondheim, Norway
}

\begin{abstract}
Since 1975, the Norwegian Geotechnical Institute has performed field investigations of snow-creep forces on masts at the research site in Grasdalen, Stryn mountains in Norway. Two poles, with diameters of 419 and $219 \mathrm{~mm}$, respectively, were erected at the site together with a retaining structure. On both poles, strain gauges were mounted in pairs every $0.5 \mathrm{~m}$ to find the axial stresses and the moments in different sections. In the middle section of the retaining structure, the beams and supporters were instrumented to obtain measurements of the strains and stresses. Snow glide was controlled by glide shoes mounted at the rock surface above the structures.

During the winter, snow profiles were made systematically; these included measurements of snow depth, density and temperature, and observations of snow type and moisture content. By relating the measured stresses and moments in the structures to the snow depth, it was possible to find the snow-pressure distribution. A comparison of the snow pressures with the "Body force index" (product of snow depth $h$, density $\rho$ and acceleration due to gravity $g$ ), show a close relationship for the wall element. For the pole elements, the snow temperature during the winter is an added factor of high importance and the highest pressures on these elements occur in winters with long periods of $0^{\circ} \mathrm{C}$ isothermal snowpack.
\end{abstract}

\section{INTRODUCTION}

Because snow creep causes failure in masts almost every winter, the Norwegian Water Resourses and Electricity Board (NVE), which is responsible for the electricity transmission lines, was interested in co-operating with the Norwegian Geotechnical Institute (NGI) to develop a study of snow-creep forces on different masts. The goal was to find new mast types which could be used in terrain with deep snow and to find design criteria for different constructions.

The research site is a $40 \mathrm{~m}$ wide and $30 \mathrm{~m}$ long rock surface tilting at $25^{\circ}$ to the east, and the masts were located at an elevation of $1150 \mathrm{~m}$ a.s.l. in the lower part of this site. The investigations were performed close to NGI's field station in the Styn mountains, $100 \mathrm{~km}$ from the coast in western Norway, where the coastal climate has a strong influence on the weather and snow conditions. The average annual precipitation in this area is close to $3 \mathrm{~m}$. At the site, the maximum snow depth, which occurs each winter between late March and early May, varies between 2 and $6 \mathrm{~m}$.

Different types of masts and a retaining structure were erected in 1975 (Larsen, 1982). As Nature is unpredictable concerning weather and snow conditions, it took years to discover design load situations. For the retaining structure, a clear relationship was discovered between the snow pressure and the "Body force index" (product of snow depth $h$, density $\rho$ and acceleration due to gravity $g$ ) (McClung and others, 1984; Larsen and others, 1985). In the late 1980s and early 1990s, new relationships of interest were found for the single-pole elements that totally changed the previous conceptions; they showed that the pressure on a single-pole element is strongly influenced by the temperature in the snowpack during the winter.

\section{INSTRUMENTATION}

Two instrumented tube-formed poles and a retaining structure were used as elements in the project. In 1975, a $6 \mathrm{~m}$ high tube-formed mast with a $419 \mathrm{~mm}$ diameter was erected perpendicular to the slope. Another mast, $4.5 \mathrm{~m}$ high, and with a $219 \mathrm{~mm}$ diameter, was erected on the slope in 1983.

Each mast was instrumented with vibrating-wire strain gauges every $0.5 \mathrm{~m}$ to obtain the axial stresses and moments at different heights (Larsen and others, 1989). A retaining structure, which is a standard element in avalanche-protection measures, was also erected at the same site in 1975 in order to investigate the snow-creep forces on the wall element. This structure comprised three $5 \mathrm{~m}$ long and $3.2 \mathrm{~m}$ high sections; only the middle section was instrumented with strain gauges to obtain measurements of the stresses in beams and supporters (Larsen and others, 1985).

Prior to 1987, the strain data were transmitted to NGI's research station at an elevation of $930 \mathrm{~m}, 700 \mathrm{~m}$ downslope from the site. During the last 10 years, a data logger at the site has been used to register information during the winter. This logger made it possible to read the instruments as often as necessary; for practical reasons every 6 hours. The first mast and retaining structure functioned throughout the investigation period of 21 years. The second mast broke in 1989 and had a functional period of only 5 years.

During the winters there was a control of the glide at the snow-ground interface. Gliding movement was found to be within a $1 \mathrm{~cm}$ range during the winter until maximum forces on the structures occurred. Snow pits were dug every fortnight to investigate the snow temperature, density, humidity, crystals and layering. The snow depth was measured every 2 weeks during the first part of the winter and 


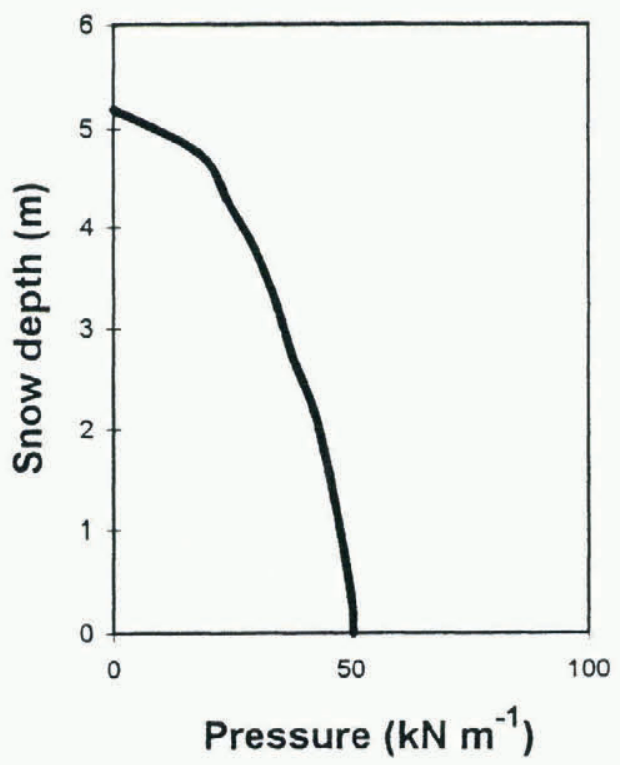

Fig. 1. Typical distribution of pressure on the $419 \mathrm{~mm}$ pole.

weekly during the last part. The weather throughout the winter was recorded at the research station $700 \mathrm{~m}$ from the constructions.

\section{RESULTS}

The stresses in different sections of the masts were computed from the strains. Measurements showed that the load increased with depth below the surface of the snow. The load distributions for the single elements showed an almost linear increase with depth in the early winter but tended to be more evenly distributed throughout the depth when the pressure was at its maximum in late winter (Fig. 1).

The distribution for the wall element was different, with the highest pressure in the middle height of the element for the whole winter (Fig. 2) (McClung and others, 1984).

The total snow pressure is generally dependent on the snow depth and average snow density. As these factors normally increase throughout the winter, the pressure gradually increases towards a maximum at the time when the snow reaches the $0^{\circ} \mathrm{C}$ isothermal (Larsen and others, 1985).

For three winters, the snow pressures at the poles showed irregularities which previously were difficult to explain. This was first recognized in 1981 with extraordinary high bending moments in the pole construction when the maximum snow depth was $4 \mathrm{~m}$ (Larsen and others, 1989). Later, the winters of 1989 and 1990 showed the same tendencies with maximum snow depths of 4.9 and $5.5 \mathrm{~m}$ (Table 1). The snow pressures during these years were between two and three times those recorded in other winters with similar snow depth and densities, for example, during the winters of 1976, 1983 and 1984.

The pressures at the wall structure did not show any differences when comparing the data from these winters with data from the other winters with the same snow depth and densities (Larsen and others, 1985).

The third factor measured throughout the winter, the snow temperature, obviously had an influence on the snow creep behaviour. In a normal winter, the snowpack has an almost linear temperature profile with the lowest values measured close to the surface and an approximate temper20

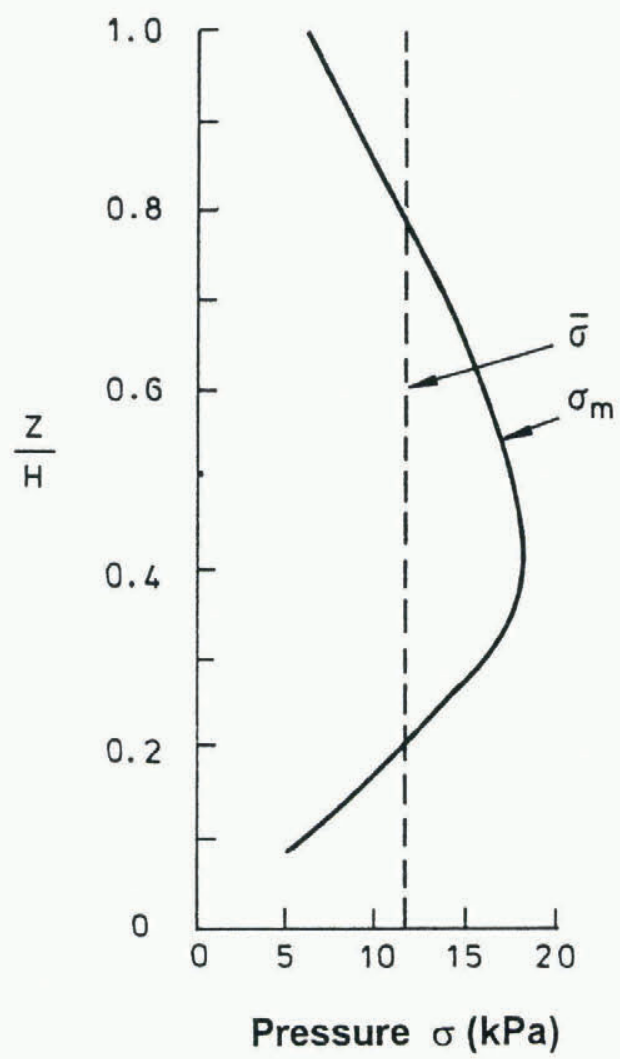

Fig. 2. Typical distribution of pressure on a retaining structure. $\sigma_{\mathrm{m}}$ is maximum and $\bar{\sigma}$ average pressure.

Table 1. Loads and snow parameters for the $419 \mathrm{~mm}$ pole

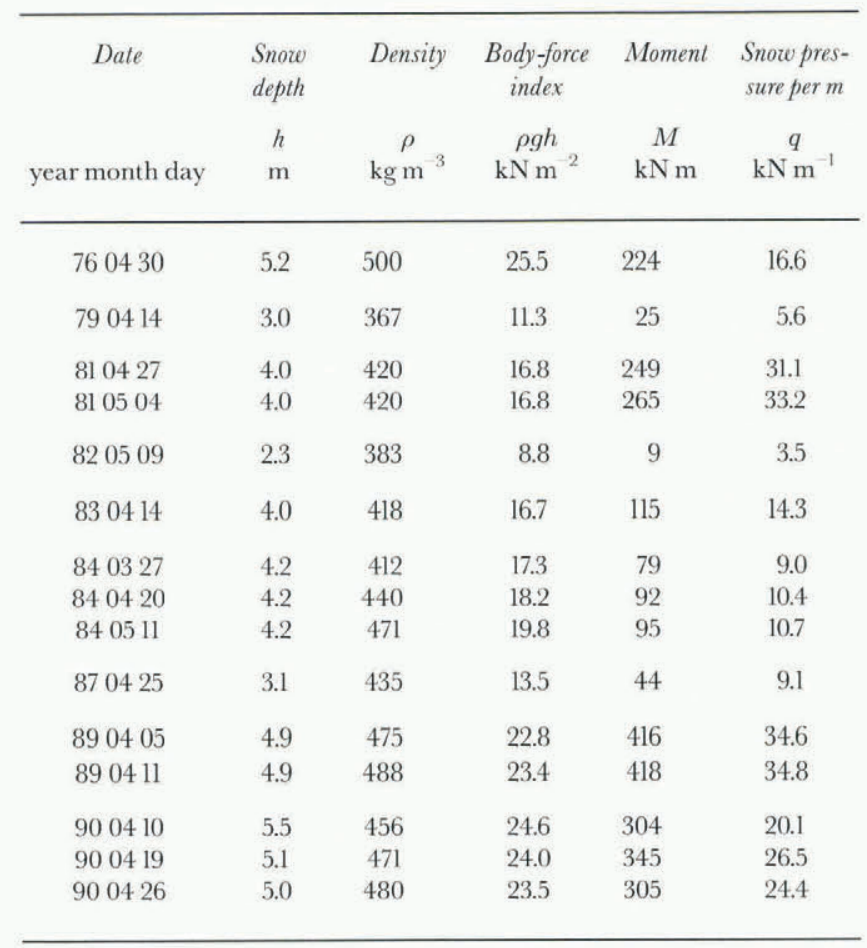

ature of $0^{\circ} \mathrm{C}$ at the snow-ground interface. The temperature in the middle depth of the snowpack gives a good indication of the temperature conditions in the snow (Larsen and others, 1989). Roughly, this temperature profile remains the same throughout the winter until mid- or late-April, when the snow reaches the $0^{\circ} \mathrm{C}$ isothermal in the research field.

During the winter of 1981, the normal temperature profile remained the same throughout January but in early 
February the temperature was close to $0^{\circ} \mathrm{C}$ throughout the whole snow cover (Larsen and others, 1985). The same thing happened in 1989 and 1990. On 8 March 1989, the lowest temperature measured below the surface of a $5 \mathrm{~m}$ deep snow pack was $-0.3^{\circ} \mathrm{C}$ and the snow temperature remained close to $0^{\circ} \mathrm{C}$ for the rest of the winter. On 6 February 1990, the mid-depth temperature was approximately $0^{\circ} \mathrm{C}$ in a $2.2 \mathrm{~m}$ deep snow pack. As the snow depth exceeds $4 \mathrm{~m}$ in the beginning of March, only the upper $1.5 \mathrm{~m}$ were colder than $0^{\circ} \mathrm{C}$, and as the snow depth increased to $5 \mathrm{~m}$ at the end of March, only the $0.5 \mathrm{~m}$ closest to the surface had freezing temperatures.

Based on these results, the pressure for the design of a mast construction can be expressed by:

$$
q=K \rho g h^{2} C \sin \alpha
$$

where $q$ is average pressure on the mast $\left(\mathrm{kN} \mathrm{m}^{-1}\right)(q \times h=$ total snow pressure), $h$ is snow depth near the mast (measured perpendicular to the ground surface) (m), $K$ is a factor, depending on snow depth: 1.2 for a snow depth of $4 \mathrm{~m}$ and 0.7 for a snow depth of $5 \mathrm{~m}, \rho$ is average snow density $\left(\mathrm{kg} \mathrm{m}^{-3}\right), g$ is acceleration due to gravity $\left(\mathrm{m} \mathrm{s}^{-2}\right), C=0.98 d^{0.63}+0.42$ where $d$ is mast diameter $(\mathrm{m})$ and $\alpha$ is slope inclination in degrees.

The $219 \mathrm{~mm}$ mast was active only in a few cold winters but, by comparison with the average pressure $q$ acting on masts with different diameters, we obtained a dependency between pressure and diameter which can be expressed by the factor $C$ in the pressure equation.

\section{DISGUSSION}

A single element such as a pole will have an influence zone which is vastly wider than the diameter of the pole (Bader and others, 1939). The influence zone above the pole will also be dependent on rate and time of the snow-creep process. High creep rate and a long influence time will increase both the influence zone and the pressure. From the observations, there seems to be a connection between the time of loading from the $0^{\circ} \mathrm{C}$ isothermal snowpack and the pressure recorded. Different from the observations of Bader and others (1939), the pole has only a compression zone and no tension zone, because the snow creep creates an open space on the tension side of the structure in late winter when the pressure is at its peak value (Fig. 3).

The retaining structure does not show the same increase in pressure in the winters with a long period of $0^{\circ} \mathrm{C}$ isothermal snowpack, because the measurements were carried out on the mid-section of the structure. There is no significant effect of an increase in the influence zone for the midsection as there is for the pole itself. If the investigations had been at the end section of the structure, the same effect as for the pole would probably have been recognized.

The expressions given for calculating the forces on a pole element are found from the measured peak values at the site. Further investigations are needed to obtain more accurate values for $K$ and $C$. The results will also be used in the future to develop a general numerical model for the design of masts.

\section{CONGLUSION}

The snow-creep forces on masts are strongly dependent on the temperature development in the seasonal snowpack. A

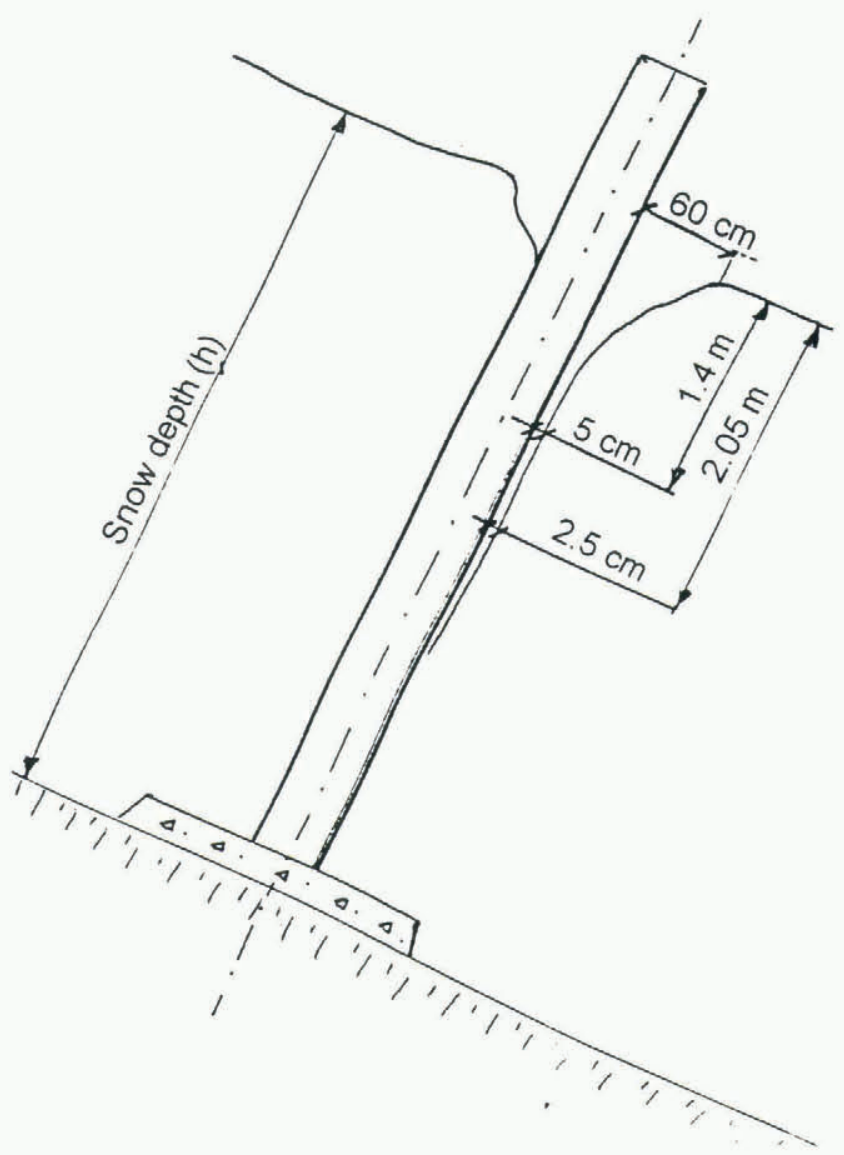

Fig. 3. Snow distribution around the pole in late-winter.

$0{ }^{\circ} \mathrm{C}$ isothermal snowpack, with a stable or increasing snow depth during most of the winter, will act differently from a normal "cold" snowpack, which tends to be isothermal at the end of the winter. This "warm" snow will develop larger influence zones and higher snow-creep pressures on single exposed elements than can be expected when the snow's temperature is below the melting point throughout most of the winter.

Especially high pressures at the edges of wall elements under the same "warm" snowpack conditions caused by similar effects should also be expected.

\section{ACKNOWLEDGEMENTS}

I am grateful to K. Kristensen, Norwegian Geotechnical Institute (NGI) for his assistance in the field work. I also wish to thank the other members of NGI's group working in Snow and Avalanche Research for their help and support.

The project was made possible partly by funding from the Norwegian Water Resources and Electricity Board.

\section{REFERENCES}

Bader, H., R. Haefeli, E. Bucher, J. Neher, O. Eckel and C. Thams. 1939. Der Schnee und seine Metamorphose. Beitr. Geol. Schweiz, Geotech. - Hydrol. 3.

Larsen, J. O. 1982. Snoens sigetrykk mot konstruksjoner ibratt terreng. Oslo, Norges Geotekniske Institutt. (NGI Rapport 75420/58110-1.)

Larsen, J. O., D. M. McClung and S. B. Hansen. 1985. The temporal and spatial variation of snow pressure on structures. Can. Geotech. J., 22(2), 166-171.

Larsen, J. O., J. Laugesen and K. Kristensen. 1989. Snow-creep pressure on masts. Ann. Glaciol., 13, 154-158.

McClung, D. M., J. O. Larsen and S. B. Hansen. 1984. Comparison of snow pressure measurements and theoretical predictions. Can. Geotech. J., 21 (2), 250-258. 